\title{
Dynamic, Electronic and Optical Properties of Fm3m-HgF2: A DFT Approach
}

\author{
M VAGHELA $^{1}$, Dhara Raval ${ }^{1}$, Bindiya Babariya ${ }^{1}$, and P.N. Gajjar ${ }^{1}$ \\ ${ }^{1}$ Gujarat University
}

September 25, 2021

\begin{abstract}
In the present work, the cubic structure of $\mathrm{HgF} 2$ has been studied using generalized gradient approximation within the framework of density functional theory. Here, the positive phonon frequencies in the phonon dispersion curves show stability of the structure. The elastic constants also satisfy criteria of being kinetically stable material. The B/GH ratio 2.56 of HgF2 indicates its ductile nature. The thermodynamic intrinsic parameters of $\mathrm{HgF} 2$ have been calculated using linear response method where the temperature variations of Helmholtz free energy (F), internal energy (E), specific heat at constant volume (Cv) and Debay temperature ( D) have been studied. The explanation of the bonding nature is discussed using electronic band structure, density of states and charge density. Here, the presence of the wide valence band gap in electronic band structure and density of states displays the ionic behaviors of $\mathrm{HgF} 2$. In addition, the charge density along the [111] plane defines hybridization in between 's', 'p' and 'd' orbitals in HgF2. The optical parameters of Fm3m-HgF2 were calculated using Random Phase Approximation. Here, the found static refractive index is 1.26. The general optical study showing the trend of being transparent in most of the UV region and fully transparent in the visible region by ionic Fm3m HgF2. Also, it shows significant absorption in the entire UV region and a long absorption tail which extends into the visible region.
\end{abstract}

\section{Hosted file}

Final_JQC.docx available at https://authorea.com/users/433855/articles/538929-dynamicelectronic-and-optical-properties-of-fm3m-hgf2-a-dft-approach

\section{Hosted file}

Images content.docx available at https://authorea.com/users/433855/articles/538929-dynamicelectronic-and-optical-properties-of-fm3m-hgf2-a-dft-approach

\section{Hosted file}

Table content.docx available at https://authorea.com/users/433855/articles/538929-dynamicelectronic-and-optical-properties-of-fm3m-hgf2-a-dft-approach 